\title{
The rs4430796 SNP of the HNF1 $\beta$ gene associates with type 2 diabetes in older adults
}

\author{
Wilcelly Machado-Silva ${ }^{1}$ \\ Audrey C. Tonet-Furioso ${ }^{1}$ \\ Lucy Gomes ${ }^{2}$ \\ Cláudio Córdova ${ }^{2}$ \\ Clayton Franco Moraes ${ }^{1,2}$ \\ D Otávio Toledo Nóbrega ${ }^{1}$
}

1. University of Brasilia (UnB), Brasília - DF, Brasil. 2. Catholic University of Brasilia, Brasília - DF, Brasil.

http://dx.doi.org/10.1590/1806-9282.64.07.586

\section{SUMMARY}

INTRODUCTION: The impact of type 2 diabetes mellitus raises interest in understanding its evolutionary-genetic basis, to unveil yet unknown pathways that may have immediate medical relevance. The HNF1 $\beta$ gene (hepatocyte nuclear factor-1 beta) is a transcription factor expressed in tissues such as liver, kidney, genital tract and pancreas that is known to be essential for insulin secretion and glucose balance. We tested the association of allelic variants produced by the HNF1 $\beta$ gene (rs4430796) variation with the clinical and biochemical profile of elderly Brazilian outpatients with metabolic disorders.

MATERIAL AND METHODS: Anthropometry, blood pressure, glycaemia, lipemia and other parameters were assessed in 184 Brazilians aged 60 or older in clinical care settings. Alleles were determined by amplification of the polymorphic site by real time polymerase chain reaction.

RESULTS: Analysing variables across the genotypes, a statistically significant difference was noticed in the allele frequencies among diabetic patients, with $30.8 \%$ of the A homozygous bearing the condition compared to a prevalence of $12.2 \%$ between G homozygotes. CONCLUSION: Our results corroborate the possible protective property of the GG genotype from the rs4430796 variation (already presented in the literature) against occurrence of diabetes mellitus, which appears applicable to elderly individuals as well, even in the context of multiple metabolic disorders so typical in older Brazilians.

KEYWORDS: Diabetes mellitus. Polymorphism genetic. Aged.

Diabetes is a group of metabolic diseases characterized by hyperglycaemia resulting from defects in insulin secretion, insulin action, or both'. In 2012, an estimated 1.5 million deaths were directly caused by diabetes and another 2.2 million deaths were attributable to high blood glucose ${ }^{2}$. Type 2 diabetes mellitus (DM2) is projected to be the seventh leading cause of death worldwide by 2030 . This impact of DM2 has raised concerns and interest in under- standing its evolutionary-genetic basis, as well as in discovering underlying, yet unknown pathways that may have more immediate medical relevance ${ }^{3}$.

The hepatocyte nuclear factor-1 beta (HNF1 $\beta)$ was shown to be a transcription factor involved in the tissue-specific regulation of embryonic development as well as in the gene expression in various organs such as liver, muscle, intestine, kidney, pancreas, and the genitourinary system ${ }^{4}$. HNF1 $\beta$ is known to be essen-

DATE OF SUBMISSION: 07-Jan-2018

DATE OF ACCEPTANCE: 13-Jan-2018

CORRESPONDING AUTHOR: Otavio Nóbrega

Programa de Pós-Graduação em Ciências Médicas, Campus Universitário Darcy Ribeiro,

Faculdade de Medicina - sala B2 21/17. 2ํandar, Asa Norte, 70910-900, Brasília - DF, Brasil.

Phone: +5561- 3107 1913; +5561 98451-3718.

E-mail: otavionobrega@unb.br, otnobrega@gmail.com

wilcellym@gmail.com

ac.tonet@uol.com.br

lucygomes@pos.ucb.br

cordova@ucb.br claytonf@ucb.br 
tial for normal glucose-stimulated insulin secretion from the analysis of $\beta$-cell-conditional HNF1 $\beta$ knockout mice ${ }^{5}$. Besides leading to an impaired glucose metabolism, selective deletion of HNF1 $\beta$ in $\beta$-cells leads to a variety of islet gene expression dysregulation. Some GWAS revealed that several tag SNPs in the $H N F 1 \beta$ gene were associated with the susceptibility of DM2 and such associations were well replicated in many countries ${ }^{6}$ Thus, $H N F 1 \beta$ is prominent in the regulation of human insulin gene transcription ${ }^{7}$.

The purpose of this study was to investigate the association of allelic variants produced by the rs4430796 variation in the HNF1 $\beta$ gene with the glycaemic profile of Brazilian elderly patients as

TABLE 1. AVERAGE ANTHROPOMETRIC, CLINICAL AND METABOLIC FEATURES ACCORDING TO GENOTYPES OF THE HNF1 $\beta$ GENE.

\begin{tabular}{|c|c|c|c|}
\hline & \multicolumn{3}{|l|}{ rs4430796 } \\
\hline & $\begin{array}{l}A / A \\
(n=52)\end{array}$ & $\begin{array}{l}A / G \\
(n=83)\end{array}$ & $\begin{array}{l}\mathrm{G} / \mathrm{G} \\
(\mathrm{n}=49)\end{array}$ \\
\hline Age (years) & $73.4 \pm 9.7$ & $74.3 \pm 8.8$ & $74.9 \pm 8.5$ \\
\hline Male (\%) & 46.2 & 42.2 & 38.8 \\
\hline $\mathrm{BMI}(\mathrm{kg} / \mathrm{m} 2)$ & $27.4 \pm 4.5$ & $27.6 \pm 5.3$ & $27.4 \pm 6.0$ \\
\hline WC $(\mathrm{cm})$ & $97.2 \pm 10.2$ & $96.0 \pm 11.6$ & $96.9 \pm 14.6$ \\
\hline $\mathrm{SPB}(\mathrm{mm} \mathrm{Hg})$ & $137.5 \pm 18.3$ & $133.9 \pm 18.2$ & $137.0 \pm 22.6$ \\
\hline $\mathrm{DBP}(\mathrm{mm} \mathrm{Hg})$ & $79.4 \pm 10.6$ & $79.5 \pm 11.6$ & $80.9 \pm 11.6$ \\
\hline $\mathrm{SAH}(\%)$ & 76.9 & 75.9 & 81.6 \\
\hline $\mathrm{GLU}(\mathrm{mg} / \mathrm{dl})$ & $106.0 \pm 21.1$ & $102.9 \pm 20.3$ & $97.4 \pm 15.4$ \\
\hline HbA1c (\%) & $6.1 \pm 1.0$ & $6.0 \pm 1.0$ & $5.6 \pm 0.6^{*}$ \\
\hline DM2 (\%) & 30.8 & 31.3 & $12.2^{*}$ \\
\hline $\mathrm{CHL}(\mathrm{mg} / \mathrm{dl})$ & $187.2 \pm 33.9$ & $191.5 \pm 39.3$ & $195.8 \pm 44.8$ \\
\hline $\mathrm{HDL}(\mathrm{mg} / \mathrm{dl})$ & $48.6 \pm 10.6$ & $48.6 \pm 12.0$ & $48.4 \pm 11.1$ \\
\hline TGL (mg/dl) & $138.4 \pm 69.5$ & $131.5 \pm 51.5$ & $149.8 \pm 74.8$ \\
\hline Dyslipidemic (\%) & 51.9 & 49.4 & 51.0 \\
\hline MS (\%) & 50.0 & 60.2 & 65.3 \\
\hline $\mathrm{TSH}(\mathrm{mU} / \mathrm{l})$ & $2.1 \pm 1.5$ & $2.7 \pm 2.2$ & $2.8 \pm 2.5$ \\
\hline CRP (mg/dl) & $3.6 \pm 5.6$ & $3.4 \pm 6.0$ & $3.1 \pm 3.8$ \\
\hline CGault (ml/min) & $74.3 \pm 28.9$ & $68.4 \pm 27.3$ & $67.1 \pm 32.1$ \\
\hline $\operatorname{AST}(U / I)$ & $22.2 \pm 6.8$ & $20.3 \pm 6.2$ & $20.7 \pm 5.5$ \\
\hline $\operatorname{ALT}(U / I)$ & $19.1 \pm 8.5$ & $18.6 \pm 6.7$ & $18.6 \pm 7.2$ \\
\hline $\operatorname{gGT}(\mathrm{U} / \mathrm{I})$ & $27.3 \pm 20.1$ & $33.9 \pm 26.0$ & $30.1 \pm 22.2$ \\
\hline Sedentary (\%) & 50.0 & 59.0 & 63.3 \\
\hline Smoker (\%) & 31.4 & 40.2 & 34.7 \\
\hline
\end{tabular}

Data shown as mean \pm SD or frequency within genotype. $\pi<0.05$ when compared to any other genotypic group. $\mathrm{BMI}=$ body mass index; $\mathrm{WC}=$ waist circumference; $\mathrm{SBP}=$ systolic blood pressure; $\mathrm{DBP}=$ diastolic blood pressure; $\mathrm{SAH}=$ systemic arterial = type 2 diabetes mellitus; $\mathrm{TGL}=$ triglycerides; $\mathrm{CHL}=$ total cholesterol; $\mathrm{HDL}=$ high density lipoprotein; MS = metabolic syndrome; TSH = thyroid stimulating hormone; CRP = C-reactive protein; CGault = Cockcroft-Gault creatinine clearance; $A S T=$ as partate aminotransferase; ALT = alanine aminotransferase; $\gamma \mathrm{GT}$ = gamaglutamiltranspeptidase. well as with their clinical, biochemical and inflammatory features.

For that, a sample of consecutive non-institutionalized patients aged 60 or older were enrolled between 2011 and 2013 at two general geriatrics outpatient clinics located at the metropolitan area of the Federal District, Brazil. The clinics were the Geriatrics Service of the Catholic University of Brasília (HUCB) and the Geriatrics Center of the University of Brasília (UnB). The main inclusion criterion was to spontaneously seek primary or secondary care for circulatory events. Exclusion to integrate these analyses were active inflammatory and/or infectious conditions, malignancies of any kind (current or past) or important kidney impairment (creatinine clearance $<25 \mathrm{ml} / \mathrm{min} / 1.73 \mathrm{~m}^{2}$ ) coupled or not with abnormal titers of liver function markers. Patient enrolment was done consecutively, with no active search for particular conditions or events. The study was approved by the institutional research ethics committee and procedures were in accordance with the ethical standards of the Helsinki Declaration, with all participants having signed informed consent before assessments.

Diagnosis of type 2 diabetes included self-report of the condition confirmed by clinical aspect in anamnesis and/or by fasting glycosylated haemoglobin $(\mathrm{Hb} 1 \mathrm{Ac}) \geq 6.5 \%$. Practitioners of physical exercises were those exhibiting 30 minutes or over of exercises at any bout for at least four days a week ${ }^{8}$, while the smoking habit was defined as report of usual, active consumption of cigarettes ${ }^{9}$. Metabolic syndrome (MS) was identified according to NCEP-ATPIII criteria ${ }^{10}$. For biochemical analysis, the following measures were obtained according to routine clinical biochemistry and expressed in standard units: blood glucose (GLU), glycated haemoglobin (HbA1c), total cholesterol (CHL), and high density lipoprotein (HDL), triglycerides (TGL), C-reactive protein high sensitivity (CRP), thyroid stimulating hormone (TSH), Cockcroft-Gault creatinine clearance (CGault), gamaglutamiltranspeptidase ( $\gamma \mathrm{GT}$ ), aspartate aminotransferase (AST) and alanine aminotransferase (ALT).

All subjects were submitted to assessments of total body mass $(\mathrm{kg})$, body height $(\mathrm{m})$, and blood pressure $(\mathrm{mmHg})$. Body mass index $\left(\mathrm{BMI} ; \mathrm{kg} / \mathrm{m}^{2}\right)$ was defined as usual whereas waist circumference (WC; $\mathrm{cm}$ ) was measured $2 \mathrm{~cm}$ above the umbilicus scar.

Whole blood was obtained during sampling for 
biochemical analysis and stored at $-20^{\circ} \mathrm{C}$ until use. Genomic DNA was purified according to standard extraction kits (QIAamp DNA Mini Kit, Qiagen, Brazil). All the patients have been genotyped for the HNF1 $\beta$ A/G transition (rs4430796). For the identification of the polymorphisms, we have used the QuantStudio 3 Real-Time PCR System (Applied Biosystems). The reactions have taken place on 96 wells plaques and in $10 \mu \mathrm{l}$ of total volume that included $2 \mu \mathrm{l}$ of a DNA preparation $(\approx 10-20 \mathrm{ng})$ and $8 \mu \mathrm{l}$ of reaction mixture constituted by $5 \mu \mathrm{l}$ of Universal Master Mix (Applied Biosystems, Foster City, CA), 0,25 $\mu$ l of TaqMan SNP Genotyping Assays 40x (Applied Biosystems, Foster City, CA) and $2,75 \mathrm{\mu l}$ of ultrapure water. The cycling conditions for the Real Time PCR QuantStudio 3 System were $50^{\circ} \mathrm{C}$ for 2 minutes (pre-read stage), $95^{\circ} \mathrm{C}$ for 10 minutes (hold stage) and PCR stage of $95^{\circ} \mathrm{C}$ for 15 seconds and $60^{\circ} \mathrm{C}$ for 1 minute for 45 cycles. Results interpretation has been achieved by means of the system QuantStudio $^{\mathrm{TM}}$ Design and Analysis Software v1.4.1.

The Kolmogorov-Smirnov test was used to test normal distribution of continuous variables through within-genotype approach. The Hardy-Weinberg equilibrium was tested using chi-square test. Data is expressed as means \pm standard deviation (SD) or frequency (\%). Analysis of variance (ANOVA) was used to compare means of the continuous variables (e.g.: age) across genotypes. Frequencies of categorical variables (e.g.: gender) across genotypes were compared using the chi-square test. All analyses were performed employing the Statistical Package for Social Sciences (SPSS) for Windows (version 13.0). A p value $<0.05$ was considered significant.

Data of the 184 patients was analysed for anthropometric, clinical and metabolic features, with mean values and proportions in Table 1. The overall profile of the patients is compatible with an important frequency of metabolic disorders, with a high prevalence of diabetic (> 30\%) dyslipidemic (> 50\%) and hypertensive $(>75 \%)$ cases as well as of smokers (> $30 \%)$ and sedentary individuals (> 50\%).

The frequencies of the HNF1 $\beta$ rs4430796 alleles in the sample were consistent with the Hardy-Weinberg equilibrium ( $p$ value $<0.05$ ). A statistically significant difference was noticed in the frequency of diabetic patients across genotypes, with $30.8 \%$ of the A homozygous bearing the condition compared to a prevalence of $12.2 \%$ between $\mathrm{G}$ homozygotes $\left(\chi^{2}=\right.$ 6.04; $\mathrm{df}=2 ; \mathrm{p}<0.05)$. Genotypes of the HNF1 $\beta$ gene associated with no other features of the sample.
Given that the HNF1 $\beta$ gene, located on $17 q 21.3$, encodes a transcription factor involved in tissue-specific regulation of gene expression and embryonic development of numerous organs ${ }^{4,11}$, and that a total of 30 heterozygous mutations in the HNF1 $\beta$ gene have been described so far (including missense, nonsense, frameshift, insertion/deletions, and splice site mutations) ${ }^{12}$, we reiterate that our investigation focused on the association of a particular A/G allelic variation (rs4430796) with a range of clinical and biochemical variables in elderly patients, having found evidence for an specific association of the corresponding GG genotype with the occurrence of T2DM. Such an association has already been described elsewhere, as follows.

The major G allele of the rs4430796 SNP of the HNF1 $\beta$ gene was associated with decreased risk of T2DM in physically active in contrast to the increased risk in sedentary, pointing out the complexity of the relationship between the gene and diabetes $^{13}$. The evidence for an association is reinforced by the genome-wide association study (GWAS) with a Chinese Hans sample which confirm the association of the HNF1 $\beta$ gene rs4430796 with T2DM (OR $\left.=1.19 ; p=1.52 \times 10^{-11}\right)^{14}$. It should be considered that the Brazilian population was formed by an admixture of races $^{15}$. In ancestry-specific GWAS meta-analyses, the rs4430796 polymorphism was also confirmed in association with T2DM (Cochran's Q $p$-value 3,6 x 10 10; $\left.p=8.9 \times 10^{-9}\right)^{16}$, as well as in another GWAS that validated this association in European, African and Asian backgrounds and found protective properties of the rs4430796 polymorphism against T2DM (OR= $\left.0.91 ; p=2.7 \times 10^{-7}\right)^{17}$.

To our knowledge, this study is the first report to demonstrate that a polymorphism in the HNF1 $\beta$ gene is associated with T2DM in Brazilian elderly patients. In clinical terms, the sample characterization revealed significant prevalence of metabolic disorders compatible with a profile eligible for primary or secondary prevention of vascular conditions. Even so, the analyses showed no association of genotypes with other basic variables apart from the glycaemic traits, rendering this relationship as plausible even in the context of multiple metabolic disorders, typical of older Brazilians ${ }^{18}$. Unfortunately, sample size severely limited statistical power for subgroup analysis. Further thorough investigations with larger sample sizes could confirm our findings.

In summary, we tested the association of allelic 
variants from the rs4430796 SNP with the clinical, biochemical and inflammatory profile in elderly patients. Our findings suggest a protective character for the GG genotype in the development of T2DM, which appears applicable to elderly individuals as well. Whether this information will prove useful for targeted prevention or treatment of type 2 diabetes remains to be determined.

\section{Author contributions}

$\mathrm{W}$. Machado-Silva carried out the genotyping procedures whereas A.C. Tonet-Furioso performed the biochemical assessments. L. Gomes and C.F. Moraes conducted the clinical/medical component of the

PALAVRAS-ChaVe: Diabetes mellitus. Polimorfismo genético. Idoso. study. C. Córdova and O.T. Nóbrega designed and coordinated the study. W. Machado-Silva and O.T. Nóbrega analysed and interpreted results as well as prepared the original manuscript.

\section{Acknowledgments}

The research was supported with grants \# 445692/2014-6 (CNPq) and \# 193.000.967/2015 (FAPDF), with a stipend to W. Machado-Silva (CAPES) and a fellowship for productivity in research to O.T. Nóbrega (CNPq).

\section{Conflict of interest}

There is no potential conflicts of interest.

\section{REFERENCES}

1. American Diabetes Association. Diagnosis and classification of diabetes mellitus. Diabetes Care. 2011;34(Suppl 1):S62-9.

2. World Health Organization. Global report on diabetes. Geneve: World Health Organization; 2016.

3. Mathers $C D$, Loncar D. Projections of global mortality and burden of disease from 2002 to 2030. PLoS Med. 2006;3(11):e442.

4. Igarashi P, Shao X, McNally BT, Hiesberger T. Roles of HNF-1beta in kidney development and congenital cystic diseases. Kidney Int. 2005;68(5):1944-7.

5. Wang L, Coffinier C, Thomas MK, Gresh L, Eddu G, Manor T, et al. Selective deletion of the Hnf1beta (MODY5) gene in beta-cells leads to altered gene expression and defective insulin release. Endocrinology. 2004;145(8):3941-9.

6. Hara K, Shojima N, Hosoe J, Kadowaki T. Genetic architecture of type 2 diabetes. Biochem Biophy Res Commun. 2014;452(2):213-20.

7. Kitanaka S, Sato U, Igarashi T. Regulation of human insulin, IGF-I, and multidrug resistance protein 2 promoter activity by hepatocyte nuclear factor (HNF)-1beta and HNF-1alpha and the abnormality of HNF-1beta mutants. J Endocrinol. 2007;192(1):141-7.

8. Physical Activity Guidelines Advisory Committee report, 2008. To the Secretary of Health and Human Services. Part A: executive summary. Nutr Rev. 2009;67(2):114-20.

9. Backinger $C L$, Fagan $P, O^{\prime}$ Connell ME, Grana R, Lawrence D, Bishop IA, et al. Use of other tobacco products among U.S. adult cigarette smokers: prevalence, trends and correlates. Addict Behav. 2008;33(3):472-89.

10. Wanless IR, Bargman JM, Oreopoulos DG, Vas SI. Subcapsular steatonecrosis in response to peritoneal insulin delivery: a clue to the pathogenesis of steatonecrosis in obesity. Mod Pathol. 1989;2(2):69-74.

11. Tronche F, Yaniv M. HNF1, a homeoprotein member of the hepatic transcription regulatory network. Bioessays. 1992;14(9):579-87.
12. Edghill EL, Bingham C, Ellard S, Hattersley AT. Mutations in hepatocyte nuclear factor-1beta and their related phenotypes. J Med Genet. 2006;43(1):84-90.

13. Brito EC, Lyssenko V, Renström F, Berglund G, Nilsson PM, Groop L, et al. Previously associated type 2 diabetes variants may interact with physical activity to modify the risk of impaired glucose regulation and type 2 diabetes: a study of 16,003 Swedish adults. Diabetes. 2009;58(6):1411-8.

14. Li H, Gan W, Lu L, Dong X, Han X, Hu C, et al. A genome-wide association study identifies GRK5 and RASGRP1 as type 2 diabetes loci in Chinese Hans. Diabetes. 2013;62(1):291-8.

15. Kehdy FS, Gouveia MH, Machado M, Magalhães WC, Horimoto AR, Horta BL, et al. Origin and dynamics of admixture in Brazilians and its effect on the pattern of deleterious mutations. Proc Natl Acad Sci U S A. 2015;112(28):8696-701.

16. DIAbetes Genetics Replication And Meta-analysis (DIAGRAM) Consortium; Asian Genetic Epidemiology Network Type 2 Diabetes (AGEN-T2D) Consortium; South Asian Type 2 Diabetes (SAT2D) Consortium; Mexican American Type 2 Diabetes (MAT2D) Consortium; Type 2 Diabetes Genetic Exploration by Nex-generation sequencing in muylti-Ethnic Samples (T2D-GENES) Consortium, Mahajan A, Go MJ, Zhang W, Below JE, Gaulton KJ, Ferreira T, et al. Genome-wide trans-ancestry meta-analysis provides insight into the genetic architecture of type 2 diabetes susceptibility. Nat Genet. 2014;46(3):234-44.

17. Gudmundsson J, Sulem P, Steinthorsdottir V, Bergthorsson JT, Thorleifsson G, Manolescu A, et al. Two variants on chromosome 17 confer prostate cancer risk, and the one in TCF2 protects against type 2 diabetes. Nat Genet. 2007;39(8):977-83.

18. Nóbrega OT, Faleiros VP, Telles JL. Gerontology in the developing Brazil: achievements and challenges in public policies. Geriatr Gerontol Int. 2009;9(2):135-9. 